\title{
Smooth surface induced glossy appearance of freestanding multiwall carbon nanotube sheet
}

\author{
Rahmat Agung Susantyoko ${ }^{1}$ (D) Noura Aldarmaki ${ }^{1} \cdot$ Zainab Karam $^{1} \cdot$ Ibrahim Mustafa $^{1} \cdot$ Saif Almheiri ${ }^{1,2}$
}

Received: 31 January 2021 / Revised: 7 April 2021 / Accepted: 12 April 2021 / Published online: 6 May 2021

(c) The Author(s) 2021

\begin{abstract}
Carbon nanotube (CNT) structures reported in the literature often have a black color with low reflectance and matt surface appearance. Only a few papers reported the high reflectance and glossy appearance of the CNT surface on a substrate. To our knowledge, no one has reported the glossy appearance of freestanding CNT. Herein, we have successfully fabricated a freestanding multi-walled CNT sheet with a glossy or mirror-like surface appearance. Raman spectroscopy confirmed that both matt and glossy freestanding CNT sheets have the same chemical composition. We found that the glossy freestanding CNT sheet has a relatively flat surface morphology compared to matt freestanding CNT sheet, as seen in the atomic force microscopy results. We attributed the glossy appearance due to a relatively flat surface morphology of the freestanding CNT sheet.
\end{abstract}

Keywords Glossy $\cdot$ Buckypaper $\cdot$ Carbon nanotubes $\cdot$ Freestanding $\cdot$ Mirror-like $\cdot$ Surface

\section{Introduction}

The studies of carbon nanotube (CNT) structures, such as vertically aligned multi-walled carbon nanotube (MWCNT) arrays [1,2], coating of MWCNT mats [1, 3], CNT forest $[4,5]$, CNT honeycomb structures [6], filtrated CNT coating [7], spun CNT sheet [8], were commonly focused on the black color, low reflectance, and matt surface appearance.

The density, porosity, and agglomeration were among the factors affecting the CNT structure's reflectance on a substrate. Chunnilall et al. found that MWCNT mats have higher reflectance than vertically aligned MWCNT arrays, because the MWCNT mats were denser and less porous than vertically aligned MWCNT arrays [1]. Tomlin et al. reported that oxygen plasma reduced the vertically aligned CNT's reflectance by modifying the surface morphology, characterized

Rahmat Agung Susantyoko

rahmat.a.susantyoko@alum.mit.edu

Saif Almheiri

contact@saifalmheiri.com

1 Department of Mechanical Engineering, Masdar Institute, Khalifa University of Science and Technology, Masdar City, P.O. Box 54224, Abu Dhabi, United Arab Emirates

2 DEWA R\&D Center, Dubai Electricity and Water Authority (DEWA), Dubai, United Arab Emirates by etching away the top layer and inducing agglomeration of nanotube tips [2]. Wood et al. found that the significant factor dictating a CNT forest's reflectance is the surface structure of the misaligned CNTs in the forest's top layer. The CNT density and defects had more effects instead of forest height [4]. Rana et al. observed that the densification process reduced the bare CNT forest's porosity, induced less penetration of incident light, which increases the reflectance of the densified VACNTs compared to the bare CNT forest [5]. Udorn et al. reported that cells with average areas smaller than $30 \mu \mathrm{m}^{2}$ showed a higher total reflectance than as-synthesized CNT forest [6]. Martinez et al. reported that densified spun CNT sheet has slightly higher reflectance compared to non-densified spun CNT sheet, probably due to smoother surface [8].

Few research groups reported the high reflectance and glossy appearance of CNT surface, such as bent CNT forest [9-13] and slope control of temperature profile growth of vertically aligned CNT [14]. Atomic force microscopy (AFM) showed the low surface roughness of the top surface of bent CNT forest [12]. A selective high-density layer of the top portion of vertically aligned CNT structures induced high reflectance [14]. Both the bent CNT forest and slope control of temperature profile growth of vertically aligned CNT were not freestanding; they were grown on typically silicon substrates. To our knowledge, no one has reported the 
glossy appearance of freestanding CNT. Herein, we investigated the glossy appearance of the freestanding CNT sheet.

\section{Experimental details}

\subsection{Fabrication of glossy and matt MWCNT sheets}

Matt multi-walled carbon nanotube (MWCNT) sheet was fabricated based on the procedures outlined in reference [15] using micro-pyramid copper supporting substrate. The procedure was: Initially, $400 \mathrm{mg}$ of MWCNT flake (Applied NanoStructured Solutions; product code: ANS-ECF-01-000PEG01), $10 \mathrm{ml}$ ethanol (Sigma-Aldrich; purity $\geq 99.8 \%$ ), and $10 \mathrm{ml}$ de-ionized water (Purite Select Fusion; $\geq 18 \mathrm{M} \Omega . \mathrm{cm}$ ) were mixed inside a mortar for $2 \mathrm{~min}$. Then, the mixture was transferred to a beaker; subsequently, $90 \mathrm{ml}$ de-ionized water and $90 \mathrm{ml}$ ethanol were added. Simultaneous sonication and stirring were performed using Ultrasonic Processor (Sonic; VCX 750) and an advanced hotplate stirrer (VWR) at room temperature. Process parameters were set as follows: $40 \%$ amplitude (30-33 Watts; $>18,000 \mathrm{~J}$ ) for $10 \mathrm{~min}$, with $1000 \mathrm{rpm}$ stirring for the first $2 \mathrm{~min}$ and $1600 \mathrm{rpm}$ for the remaining $8 \mathrm{~min}$. The dispersed slurry was then degassed using a vacuum oven (BINDER; VD 53). The casting was performed manually at room temperature using a micrometer adjustable film applicator (MTI Corporation; EQ-SeKTQ-150) with a $5 \mathrm{~mm}$ doctor-blade gap above the matt side of a copper foil (MTI Corporation; EQ-bccf-9u) for matt MWCNT sheet. The casted film was then dried in a forced convection oven (BINDER; FD 53) at $120{ }^{\circ} \mathrm{C}$ for $1 \mathrm{~h}$. The dried film was then easily separated/detached from the copper substrate resulting in a matt MWCNT sheet.

Glossy MWCNT sheet was fabricated based on a similar procedure, except the following: using only the flat tempered glass (MTI Corporation; EQ-TGlass) as a supporting substrate. We observed that the yield of glossy MWCNT is much lower than the matt MWCNT sheet, as it was difficult to have separation of cast MWCNT sheet from the tempered glass. Nevertheless, a small area of glossy MWCNT sheet sample was obtained for the subsequent characterizations.

\subsection{Characterization of glossy and matt MWCNT sheets}

Scanning electron microscopy (SEM) of FEI-Thermo Fisher Scientific of Quanta 250 was used to determine the morphology of both glossy and matt MWCNT freestanding sheets. The SEM samples were not coated with a palladium/gold layer. Raman spectroscopy and atomic force microscopy (AFM) were performed using a Witec Alpha 300RAS with a $532 \mathrm{~nm}$ excitation wavelength. The specular reflectance was characterized using PerkinElmer LAMBDA
1050 spectrometer with the following configuration: incident angle of $10^{\circ}$ was used due to limitation on the signalto-noise ratio of the instrument at a higher incident angle; post-processing of plot smoothing was used to decrease the noise in the plot.

\section{Results and discussion}

Previously, we have reported MWCNT sheet with matt surface appearance (referred to as matt MWCNT sheet), which was made using industrially compatible roll-to-roll surface-engineered tape-cast (SETC) technique [15-17]. Herein, we reported the fabrication and characterization of the mirror-like (glossy) surface appearance of the MWCNT sheet (referred to as glossy MWCNT sheet). Unlike the matt MWCNT sheet, the glossy MWCNT sheet has a glossy visual appearance, as shown in Fig. 1. The specular reflectance of the glossy MWCNT sheet was significantly higher than that of the matt MWCNT sheet, see Fig. 2.

It was noted that the fabrication yield of the glossy MWCNT sheet was low compared to that of the matt MWCNT sheet. To make a glossy MWCNT sheet, we used flat tempered glass $(36 \mathrm{~cm}$ length $\times 20 \mathrm{~cm}$ width) as the supporting substrate during the tape-cast. The separation of the dried MWCNT sheet from the tempered glass was difficult without damaging the MWCNT sheet. We were lucky and able to produce a small area $(5.9 \mathrm{~cm}$ length $\times 0.4 \mathrm{~cm}$ width $=2.36 \mathrm{~cm}^{2}$ area) of the glossy MWCNT sheet. This study focused on the glossy MWCNT sheet's characterization instead of the fabrication method of the glossy MWCNT sheet.

Figure 3 shows that the Raman spectra of glossy and matt MWCNT sheets were alike. There was no difference in the Raman spectra (D, G, and 2D bands), indicating that the CNTs are alike in both samples.

The morphology and topography were characterized using Scanning Electron Microscopy (SEM) in Fig. 4 and Atomic Force Microscopy (AFM) in Fig. 5. The SEM images at 30,000 times magnification in Fig. 4 show that the glossy MWCNT sheet has a relatively smoother surface than the matt MWCNT sheet. Further quantitative characterization using AFM was performed, as shown in Fig. 5. AFM study shows the glossy MWCNT sheet has a lower roughness mean square (RMS) value of $731.80 \mathrm{~nm}$ than that of the matt MWCNT sheet of $2213.96 \mathrm{~nm}$.

Generally, specular reflection is responsible for the glossy surface on a relatively flat surface, while diffuse reflection is responsible for matt surface on a relatively rough surface. From the results of AFM, we conclude that the MWCNT sheet's glossiness originated from its flatness or low roughness of the surface roughness. The finding was relevant to the literature [12]. 
Fig. 1 Top view of a glossy MWCNT sheet and $\mathbf{b}$ matt MWCNT sheet. $\mathbf{c}$ Tilted view of glossy MWCNT sheet (a)

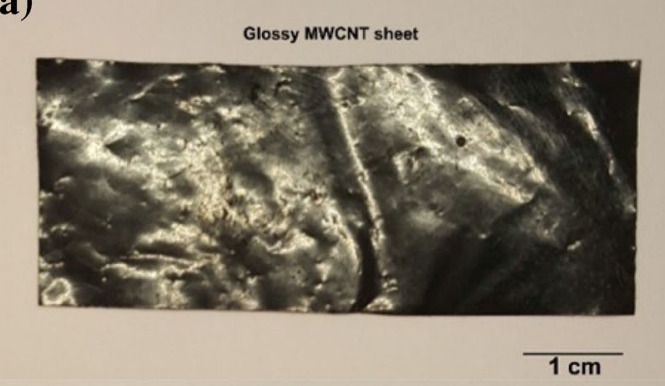

(b)

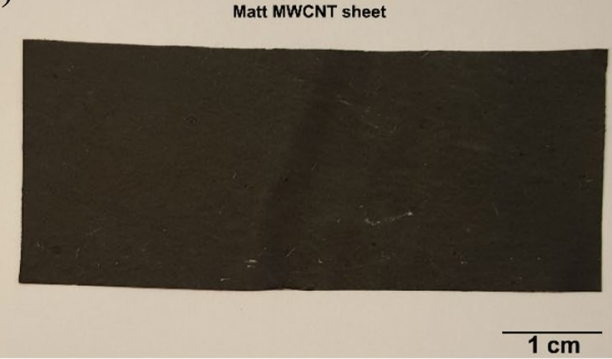

(c)

Glossy MWCNT sheet

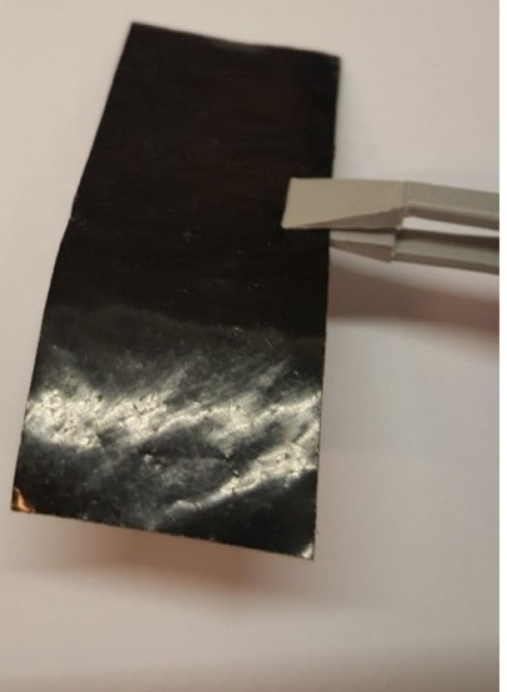

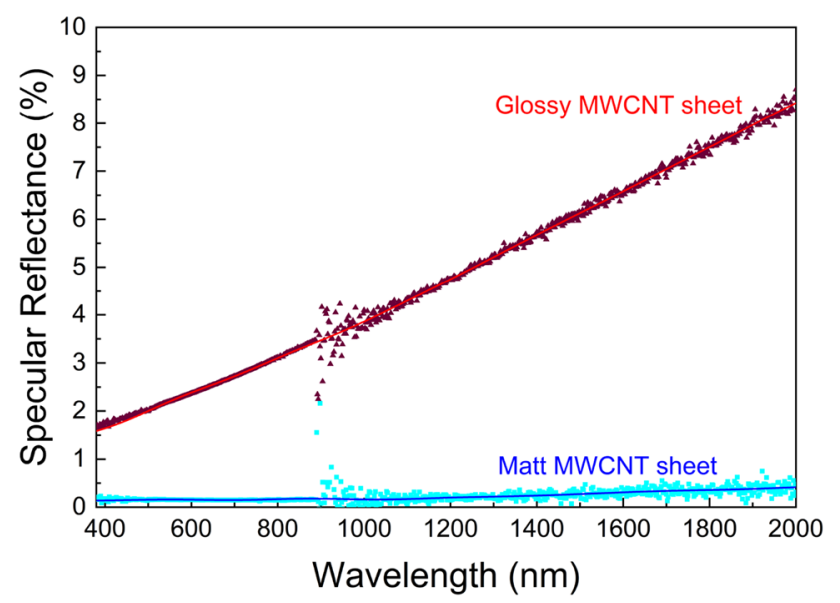

Fig. 2 Specular reflectance of glossy MWCNT sheet and matt MWCNT sheet

The glossiness can be correlated with the tape-cast fabrication process, where the MWCNT sheet followed the contour of its corresponding supporting substrate. The flat tempered glass substrate has an RMS of $187 \mathrm{~nm}$, while the micro-pyramid rough copper substrate [15] has an RMS of $448.2 \mathrm{~nm}$. We ruled out the possibility of glass contamination or glass coating on the glossy MWCNT sheet from the tempered glass substrate. The evidence is as follows. The SEM images of glossy and matt MWCNT sheets in Fig. 4 show similar morphology and shape of MWCNT with no foreign shape/particles. The Raman spectra of glossy and matt MWCNT sheets show no difference in the intensity of the $\sim 1100 \mathrm{~cm}^{-1}$ band of silicate glass [18]; see vertical dash line in Fig. 3.

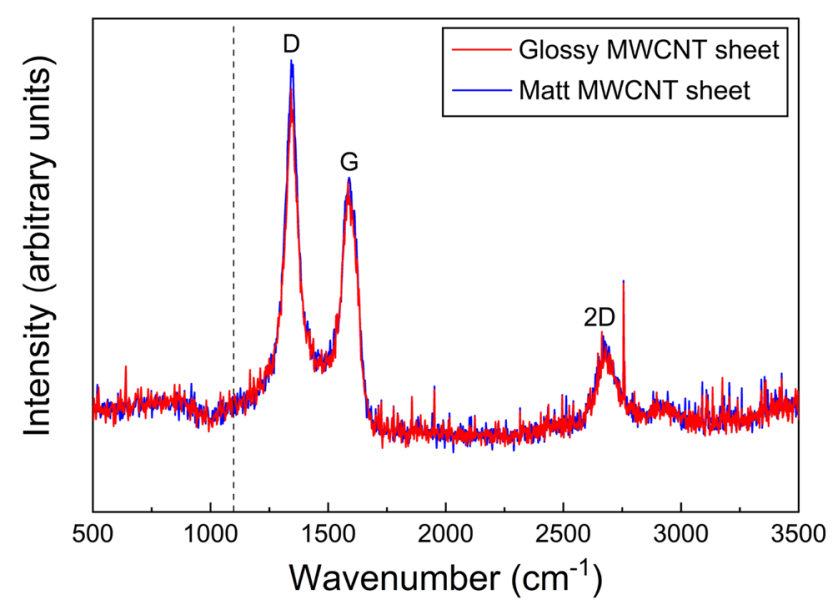

Fig. 3 Raman spectra of glossy MWCNT sheet and matt MWCNT sheet

\section{Conclusion}

We reported a freestanding MWCNT sheet with mirrorlike (glossy) surface characteristics. We characterized the glossy MWCNT sheet using a digital camera, Raman, SEM, and AFM. The results show that the glossiness originated from the flat or smooth topology of the glossy MWCNT sheet's surface. The glossy MWCNT sheet has a relatively flat surface with a root-mean-square (RMS) of $731.8 \mathrm{~nm}$, enabling more specular reflectance than the control sample of the matt MWCNT sheet with a rougher RMS of $2213.96 \mathrm{~nm}$. The demonstration of the glossy freestanding MWCNT sheet shown in this paper could 
Fig. 4 Scanning Electron Microscopy (SEM) at 30,000 times magnification of a glossy MWCNT sheet and $\mathbf{b}$ matt MWCNT sheet
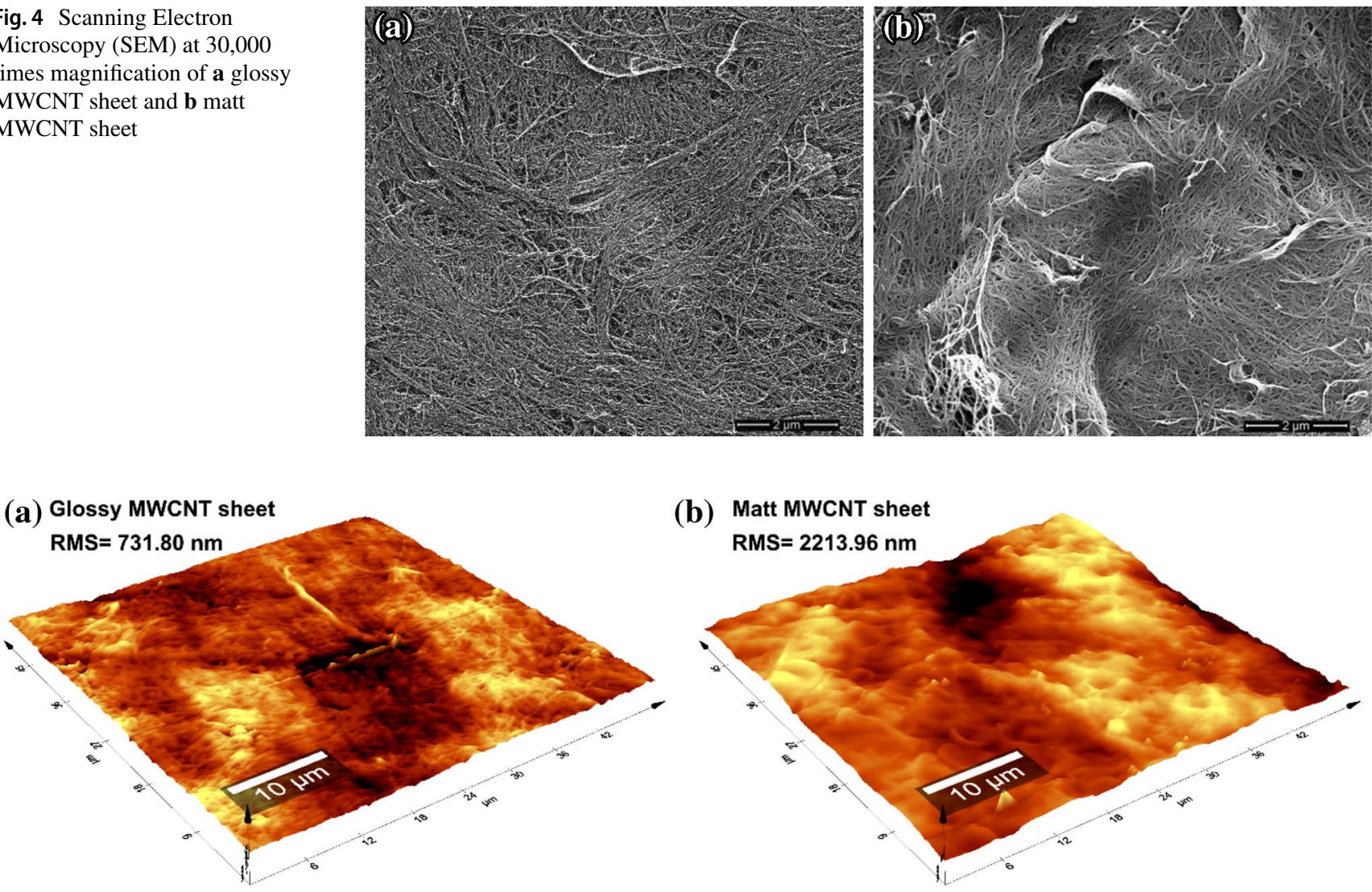

Fig. 5 Atomic Force Microscopy (AFM) mapping of a glossy MWCNT sheet and b matt MWCNT sheet

open new applications and uses in the future, characterized by higher specular reflection at the infrared region than the visible region. For future studies of glossy MWCNT sheet, Fourier Transform Infrared (FTIR) characterization, density measurement, mechanical testing, and electrical testing are recommended.

Acknowledgements The authors acknowledged the support of Applied NanoStructured Solutions LLC, a Lockheed Martin Company, for providing the MWCNT flakes.

Data availability The datasets generated during and analyzed during the current study are available from the corresponding author on reasonable request.

\section{Declarations}

Conflict of interest On behalf of all authors, the corresponding author states that there is no conflict of interest.

Open Access This article is licensed under a Creative Commons Attribution 4.0 International License, which permits use, sharing, adaptation, distribution and reproduction in any medium or format, as long as you give appropriate credit to the original author(s) and the source, provide a link to the Creative Commons licence, and indicate if changes were made. The images or other third party material in this article are included in the article's Creative Commons licence, unless indicated otherwise in a credit line to the material. If material is not included in the article's Creative Commons licence and your intended use is not permitted by statutory regulation or exceeds the permitted use, you will need to obtain permission directly from the copyright holder. To view a copy of this licence, visit http://creativecommons.org/licenses/by/4.0/.

\section{References}

1. Chunnilall CJ, Lehman JH, Theocharous E, Sanders A (2012) Infrared hemispherical reflectance of carbon nanotube mats and

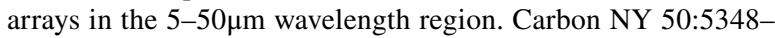
5350. https://doi.org/10.1016/j.carbon.2012.07.014

2. Tomlin NA, Curtin AE, White M, Lehman JH (2014) Decrease in reflectance of vertically-aligned carbon nanotubes after oxygen plasma treatment. Carbon NY 74:329-332. https://doi.org/ 10.1016/j.carbon.2014.03.040

3. Lehman J, Yung C, Tomlin N, Conklin D, Stephens M (2018) Carbon nanotube-based black coatings. Appl Phys Rev. https:// doi.org/10.1063/1.5009190

4. Wood BD, Dyer JS, Thurgood VA, Tomlin NA, Lehman JH, Shen T-C (2015) Optical reflection and absorption of carbon nanotube forest films on substrates. J Appl Phys 118:013106. https://doi. org/10.1063/1.4923390

5. Rana M, Razib M, Saleh T, Muthalif AGA (2016) Enhancement of reflectance of densified vertically aligned carbon nanotube forests. Carbon Lett 18:67-70. https://doi.org/10.5714/CL.2016.18.067 
6. Udorn J, Hatta A, Furuta H (2016) Carbon nanotube (CNT) honeycomb cell area-dependent optical reflectance. Nanomaterials 6:202. https://doi.org/10.3390/nano6110202

7. Weisenseel B, Zierath B, Fey T, Greil P (2016) Adjustment of the optical properties of dispersion derived carbon nanotube coatings. Adv Eng Mater 18:624-631. https://doi.org/10.1002/adem.20150 0343

8. Martinez PM, Pozdin VA, Papadimitratos A, Holmes W, Hassanipour F, Zakhidov AA (2017) Dual use of carbon nanotube selective coatings in evacuated tube solar collectors. Carbon NY 119:133-141. https://doi.org/10.1016/j.carbon.2017.04.026

9. Saleh T, Moghaddam MV, Mohamed Ali MS, Dahmardeh M, Foell CA, Nojeh A, Takahata K (2012) Transforming carbon nanotube forest from darkest absorber to reflective mirror. Appl Phys Lett 101:061913. https://doi.org/10.1063/1.4744429

10. Mukherjee S, Misra A (2014) Broadband wavelength-selective reflectance and selective polarization by a tip-bent vertically aligned multi-walled carbon nanotube forest. J Phys D Appl Phys 47:235501. https://doi.org/10.1088/0022-3727/47/23/235501

11. Mohd Razib M, Saleh T, Hassan MA (2014) Micro-mechanical bending $\left(\mathrm{M}^{2} \mathrm{~B}\right)$ method for carbon nanotube $(\mathrm{CNT})$ based sensor fabrication. In: 2014 IEEE int conf smart instrumentation meas appl IEEE, pp. 1-5. https://doi.org/10.1109/ICSIMA.2014.70474 40

12. Asyraf MRM, Rana MM, Saleh T, Fan HDE, Koch AT, Nojeh A, Takahata K, Suriani AB (2015) Study on micro-patterning process of vertically aligned carbon nanotubes (VACNTs), fullerenes. Nanotub Carbon Nanostructures. https://doi.org/10.1080/15363 83X.2015.1119126

13. Asyraf MRM, Saleh T, Islam S, Rana M, Muthalif AGA (2018) Optical characterization of tip bended vertically aligned carbon nanotubes array. Chem Phys Lett 711:37-41. https://doi.org/10. 1016/j.cplett.2018.09.011

14. Kawabata A, Murakami T, Nihei M, Yokoyama N (2013) Long length, high-density carbon nanotube film grown by slope control of temperature profile for applications in heat dissipation. Jpn J Appl Phys 52:110117. https://doi.org/10.7567/JJAP.52.110117

15. Susantyoko RA, Karam Z, Alkhoori S, Mustafa I, Wu C-H, Almheiri S (2017) A surface-engineered tape-casting fabrication technique toward the commercialisation of freestanding carbon nanotube sheets. J Mater Chem A 5:19255-19266. https://doi.org/ 10.1039/C7TA04999D

16. Karam Z, Susantyoko RA, Alhammadi A, Mustafa I, Wu C-H, Almheiri S (2018) Development of surface-engineered tape-casting method for fabricating freestanding carbon nanotube sheets containing $\mathrm{Fe} 2 \mathrm{O} 3$ nanoparticles for flexible batteries. Adv Eng Mater 20:1701019. https://doi.org/10.1002/adem.201701019

17. Almazrouei A, Susantyoko RA, Wu C-H, Mustafa I, Alhammadi A, Almheiri S (2019) Robust surface-engineered tapecast and extrusion methods to fabricate electrically-conductive poly(vinylidene fluoride)/carbon nanotube filaments for corrosionresistant 3D printing applications. Sci Rep 9:9618. https://doi.org/ 10.1038/s41598-019-45992-5

18. Fukumi K, Hayakawa J, Komiyama T (1990) Intensity of raman band in silicate glasses. J Non Cryst Solids 119:297-302. https:// doi.org/10.1016/0022-3093(90)90302-3

Publisher's Note Springer Nature remains neutral with regard to jurisdictional claims in published maps and institutional affiliations. 